ISSN 2072-6651

www.mdpi.com/journal/toxins

Article

\title{
Nivalenol Has a Greater Impact than Deoxynivalenol on Pig Jejunum Mucosa in Vitro on Explants and in Vivo on Intestinal Loops
}

Sophal Cheat ${ }^{1,2,3, \dagger, *}$, Juliana R. Gerez ${ }^{1,2,4, \dagger}$, Juliette Cognié ${ }^{5}$, Imourana Alassane-Kpembi ${ }^{1,2,6}$, Ana Paula F. L. Bracarense ${ }^{4}$, Isabelle Raymond-Letron ${ }^{7,8}$, Isabelle P. Oswald ${ }^{1,2}$ and Martine Kolf-Clauw ${ }^{1,2, *}$

1 Université de Toulouse, Institut National Polytechnique-Ecole Nationale Vétérinaire (INP-ENVT), Unité Mixte de Recherche UMR 1331 Toxalim, Research Center in Food Toxicology, 23 chemin des Capelles, F-31300 Toulouse, France; E-Mail: julianarubira@hotmail.com (J.R.G.)

2 INRA, UMR 1331 Toxalim, Research Center in Food Toxicology, 180 chemin de tournefeuille F-31027 Toulouse, France; E-Mails: imourana.alassane-kpembi@toulouse.inra.fr (I.A.K.); ioswald@toulouse.inra.fr (I.P.O.)

3 Faculty of Animal Science and Veterinary Medicine, Royal University of Agriculture, P.O. box 2696, Phnom Penh, Cambodia

4 Laboratory of Animal Pathology, Universidade Estadual de Londrina, 86057-990 Londrina, Brazil; E-Mail: anapaula@uel.br

5 Plate-forme CIRE Chirurgie et Imagerie pour la Recherche et l'Enseignement UMR 085 PRC, INRA, 37380 Nouzilly, France; E-Mail: juliette.cognie@tours.inra.fr

6 Hôpital d'Instruction des Armées, Camp Guézo 01BP517 Cotonou, Benin

7 INP-ENVT, Université de Toulouse, F-31300 Toulouse, France

8 STROMALab UMR5273 UPS EFS INSERM U1031, 1 Avenue Jean Poulhes, 31403 Toulouse, France; E-Mail: i.raymond@envt.fr

$\dagger$ These authors contributed equally to this work.

* Authors to whom correspondence should be addressed;

E-Mails: s.cheat@envt.fr or sophalcheat@yahoo.com (S.C.); m.kolf-clauw@envt.fr (M.K.-C.); Tel.: +855-12555-572 (S.C.); +33-561-193-283 (M.K.-C.); Fax: +33-561-193-978 (M.K.-C.).

Academic Editor: Sven Dänicke

Received: 22 March 2015 / Accepted: 20 May 2015 / Published: 29 May 2015 


\begin{abstract}
The mycotoxins deoxynivalenol (DON) and nivalenol (NIV), worldwide cereal contaminants, raise concerns for animal and human gut health, following contaminated food or feed ingestion. The impact of DON and NIV on intestinal mucosa was investigated after acute exposure, in vitro and in vivo. The histological changes induced by DON and NIV were analyzed after four-hour exposure on pig jejunum explants and loops, two alternative models. On explants, dose-dependent increases in the histological changes were induced by DON and NIV, with a two-fold increase in lesion severity at $10 \mu \mathrm{M}$ NIV. On loops, NIV had a greater impact on the mucosa than DON. The overall proliferative cells showed $30 \%$ and 13\% decrease after NIV and DON exposure, respectively, and NIV increased the proliferative index of crypt enterocytes. NIV also increased apoptosis at the top of villi and reduced by almost half the proliferative/apoptotic cell ratio. Lamina propria cells (mainly immune cells) were more sensitive than enterocytes (epithelial cells) to apoptosis induced by NIV. Our results demonstrate a greater impact of NIV than DON on the intestinal mucosa, both in vitro and in vivo, and highlight the need of a specific hazard characterization for NIV risk assessment.
\end{abstract}

Keywords: mycotoxins; jejunum explant; loops; deoxynivalenol; nivalenol; enterocytes; histomorphology

\title{
1. Introduction
}

Fungi of the Fusarium genus commonly contaminate cereals in the temperate climatic zones of the world and contribute to poor quality grains entering the feed and food chain. Among the mycotoxins produced by Fusarium, the large group of trichothecenes is extremely prevalent, particularly deoxynivalenol (DON) for which many exposure and toxicological surveys have been carried out or reviewed recently [1,2]. Nivalenol (NIV), classified with DON as a type B trichothecene, is a biologically active metabolite of DON, present in agricultural commodities [3,4]. A large-scale data survey has indicated that DON and NIV are present in $57 \%$ and $16 \%$, respectively, of food samples collected in the European Union [5].

From their first discovery, there has been concern about the relationship between trichothecenes exposure and health damage based on both experimental toxicity and epidemiological data. Studies have shown that mycotoxins cause toxic effects in humans as well as in all animal species so far investigated, the pig being the most sensitive species [6]. Studies in laboratory and farm animals have revealed a complex spectrum of toxic effects. Experimentally, low to moderate acute oral exposure to trichothecenes cause vomiting, diarrhea and gastroenteritis, whereas higher doses cause severe damage to the lymphoid and epithelial cells of the gastrointestinal mucosa resulting in hemorrhage, endotoxemia and shock. Chronic exposure to trichothecenes can cause anorexia, reduced weight gain, diminished nutritional efficiency, neuroendocrine changes, and immune modulation. Although not as prevalent as DON [7], NIV showed higher acute toxicity than DON in animal studies, with oral LD50 values in mice of 78 and $39 \mathrm{mg} \cdot \mathrm{kg}^{-1}$ for DON and NIV, respectively [8]. NIV is of added concern for food safety but in vivo information for assessing the health risk remain scarce, and NIV toxicity is considered similar to 
DON toxicity for protecting human health [9]. At the molecular level, DON and NIV, like other trichothecenes, display multiple inhibitory effects on the primary metabolism of eukaryotic cells including the inhibition of proteins, DNA and RNA synthesis [10]. This impairment leads to altered cell proliferation in tissues with high rates of cell turnover such as spleen, bone marrow, thymus and intestinal mucosa [11].

Following ingestion of contaminated feed or food, the intestine and intestinal mucosa can be exposed to a high concentration of food contaminants, such as mycotoxins [12]. However, only a few studies have investigated the effects of mycotoxins on this target, even though there is increasing evidence that intestinal epithelium is repeatedly exposed to mycotoxins at a higher concentration than other tissues [13]. Pigs receiving $3 \mathrm{mg} / \mathrm{kg}$ feed of DON for five weeks showed significant histopathological changes compared to control animals, such as atrophy and fusion of villi and reduction of the number of goblet cells and lymphocytes [14]. Little is known about the effects of NIV on the intestinal tract of pigs. Pigs receiving 2.5 or $5 \mathrm{mg} \mathrm{NIV} / \mathrm{kg}$ of feed for three weeks, showed gastrointestinal erosions [15] and reduced enzymatic ability of the intestinal epithelium [16].

In the context of implementing the 3Rs, "Replace, Reduce, Refine" [17], in vitro and in vivo alternatives can be used to reduce the number of experimental animals. An intestinal explants-in vitro model and an intestinal loops-in vivo model have been developed for studying intestinal responses to pathogens $[18,19]$. The culture of intestinal explants allows preservation of the normal histological structure in vitro [20]. The pig jejunal explant model has previously been used to study the digestive effects of the mycotoxin DON [21-23], and to analyze the toxicity of mixtures of mycotoxins [24]. The present work was designed to compare the acute impacts of DON and NIV on pig jejunal mucosa. The above two models were used in parallel. First, a dose-response study with explants was carried out to estimate the toxic dose for DON and NIV on the mucosa, then, jejunal loops were injected with the two toxins at the selected toxic dose. In the two models, the results, assessed after 4-h of exposure, were concordant, showing a greater impact of NIV compared to DON on the intestinal mucosa.

\section{Results}

\subsection{Explants Model}

\subsubsection{Histological Analysis before and after Incubation and Effect of DMSO}

First, the effects of the culture and of DMSO on the histology of the jejunal explants were investigated. The explants were observed microscopically and scored from 22 (no lesion) to 0 . Before incubation (T0), the scores were between 16 and 21 for all explants (Figure 1 panel I). The histological lesions observed were mild edema in the lamina propria and slight dilatation of the lymphatic vessels, resulting in an average score of $18 \pm 2$ (Figure 1 panels I and IIa).

After incubation in Williams E Medium (WME) for $4 \mathrm{~h}$, with or without DMSO, the scores did not differ significantly from those of the non-incubated explants (Figure 1I), although flattened villi were apparent after this incubation period (Figure 1IIb). The mean villus height was $141 \pm 29 \mu \mathrm{m}$ in the explants incubated with WME alone and $147 \pm 41 \mu \mathrm{m}$ in the explants incubated with DMSO and did not differ significantly from the T0 results. No statistically significant difference was observed between the different incubation groups, with $0.1 \%$ DMSO, or without DMSO (Figure 1I). The scores of control 
explants with or without DMSO were grouped into a single 4-h culture control group for subsequent analyses $(n=84)$.

(I)

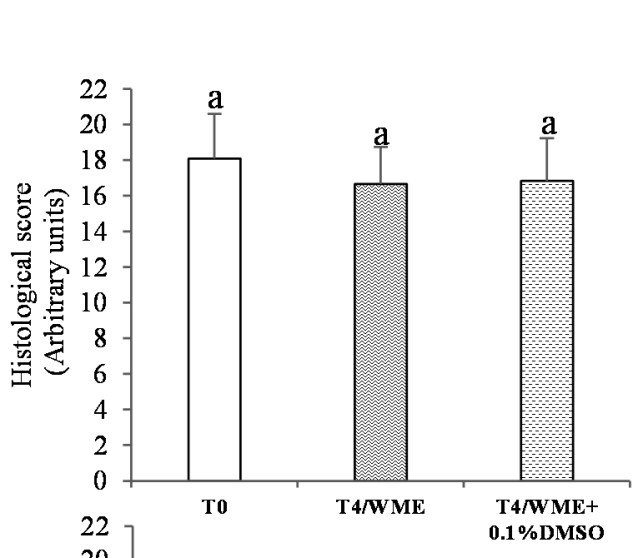

(II)

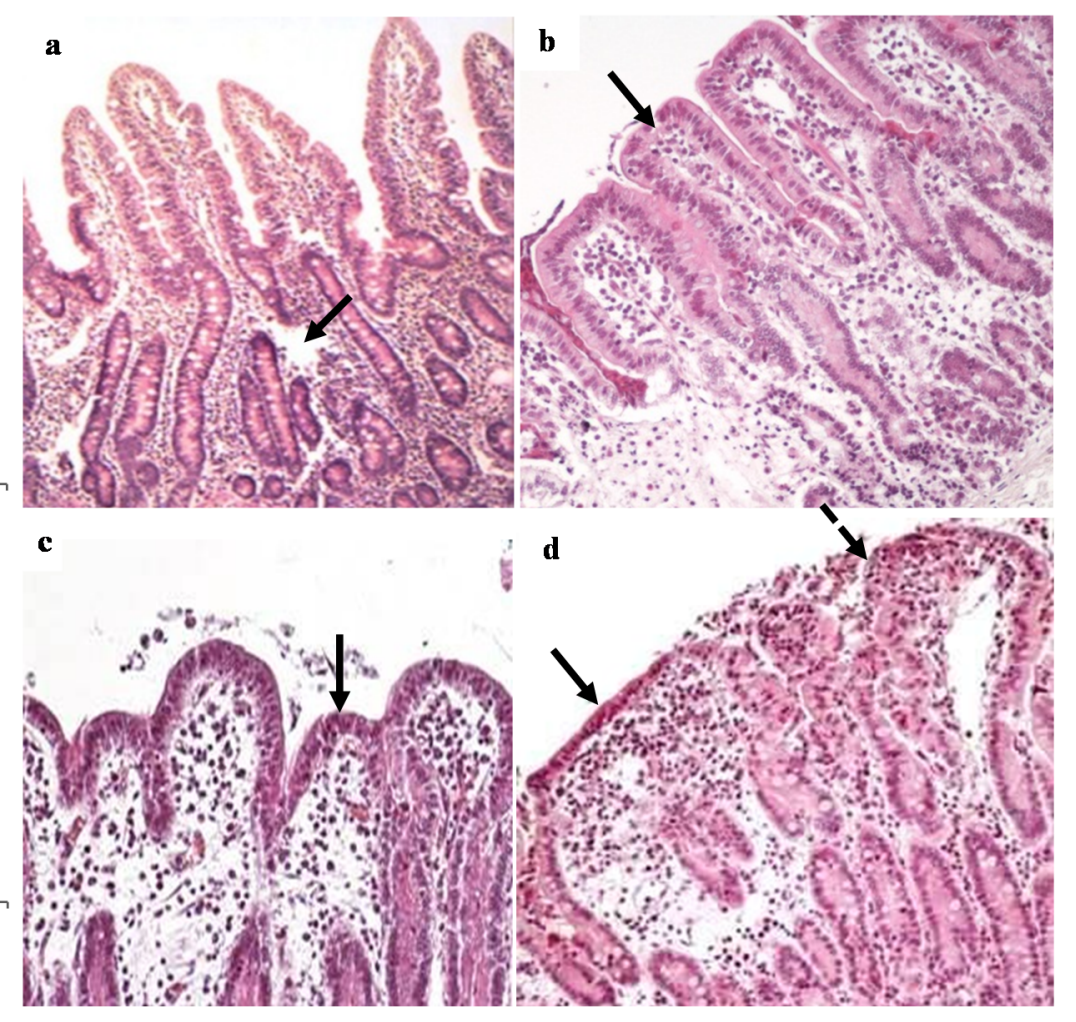

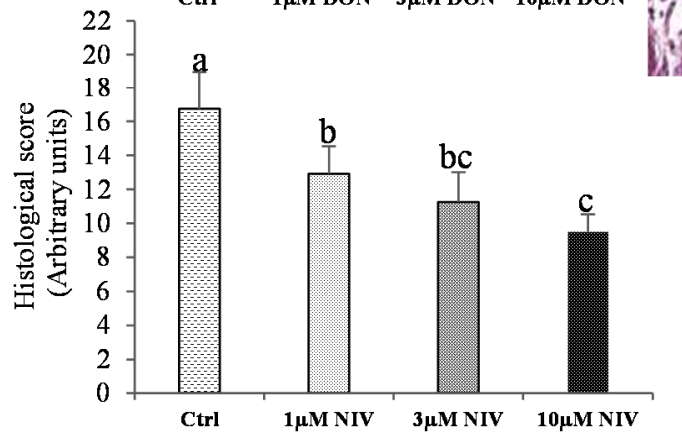

Figure 1. Histological scores of jejunal explants. (I) Explants exposed to different treatments: T0 (Time $0 \mathrm{H}$, before culture ), T4/WME (4 h in William's medium E), T4/WME $+0.1 \% \mathrm{DMSO}$ (dimethylsulfoxyde), DON (deoxynivalenol) or NIV (nivalenol): 1,3 and $10 \mu \mathrm{M}$. Values are mean \pm SEM. (II) Effect of DON and NIV on the histological score after 4 hours of exposure. Values are mean \pm SEM. a, b, c scripts are different at $p \leq 0.05$ by Tukey's test (II) (a) Jejunal explant uncultured (T0; $n=12$ ). Slight dilatation of the lymphatic vessels (arrow), HE (hematoxylin-eosin), $\times 200$; (b) explants exposed to WME with $0.1 \%$ DMSO (DMSO $n=42$ ). Edema of the lamina propria and mild villus atrophy (arrow), HE $\times 200$; (c) $3 \mu \mathrm{M}$ DON-exposed explant. Moderate fusion and cubic epithelial cells (arrow) (HE, $\times 200$ ); (d) $10 \mu \mathrm{M}$ NIV-exposed explant. Fusion and atrophy of villi with severely flattened epitelium (arrow) and apical denudation of villi (dotted arrow) (HE, $\times 200)$. 


\subsubsection{Effect of Mycotoxins on the Histological Scores}

Each treatment, DON $(1-10 \mu \mathrm{M})$ and NIV $(1-10 \mu \mathrm{M})$ induced a dose-dependent decrease in the histological scores of the jejunal explants after $4 \mathrm{~h}$ of exposure $(p<0.01)$ (Figure 1II). In the explants exposed to DON, the main morphological change was coalescence with moderate fusion of villi. Lesions included cubic epithelial cells instead of the cylindrical epithelial cells seen in the control, areas of edema in the lamina propria, villus atrophy and apical denudation of villi with focal loss of apical enterocytes (Figure 1IIc). In the group treated with NIV, the changes were similar to those of the group exposed to DON but both the flattening of the epithelial cells and apical denudation of the villi were more severe (Figure 1IId). The individual treatments with the mycotoxins DON and NIV resulted in a significant decrease of the histological score from doses of $3 \mu \mathrm{M}$ and $1 \mu \mathrm{M}$, respectively. The corresponding scores were reduced to about $70 \%$ of the control explants by $3 \mu \mathrm{M}$ and $10 \mu \mathrm{M}$ DON or $1 \mu \mathrm{M}$ NIV, to almost half the mean score of control explants $(59 \% \pm 6 \%)$ by the highest NIV concentration (Figure 1II). So, NIV showed greater toxicity than DON in the explant model, with a lowest observed effect concentration of $1 \mu \mathrm{M}$.
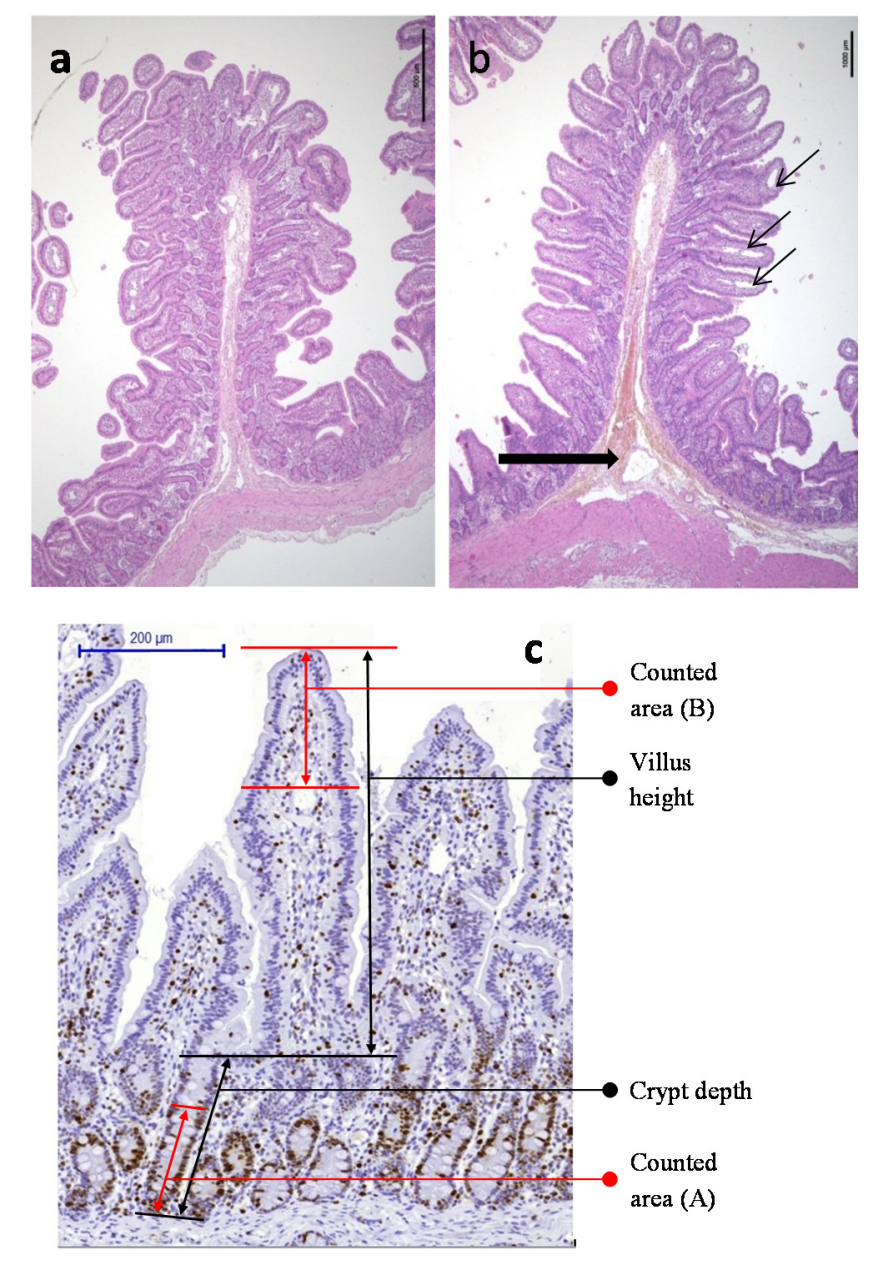

Figure 2. Jejunum morphology in a non-loop segment (a) and in a control loop (b) showing vascular changes in the submucosa (large arrow) and edema of the villi central lymphatic vessels (thin arrows); (c) Ki-67 immunostaining in a control loop, showing the methodology for morphometric and proliferation assessments. 


\subsection{Loops Model}

\subsubsection{Comparison of Loops Segments with Non-Loops Segments}

The surgery induced vascular disorders in the loops, more pronounced in the serosa and submucosa layers, with moderate interstitial edema, congestion, focal blood extravasation and moderate focal dilation of the central lacteal in the villi tips (Figure 2b). The proliferation and apoptosis counts did not differ between the control loops and non-loops segments, and were subsequently used as endpoints after toxins exposure.

\subsubsection{Effect of DON and NIV Exposure on Morphometry in the Loops}

The mean crypt-depth to villus-height ratios after DON $(0.99 \pm 0.15)$ and NIV (1.01 \pm 0.16$)$ treatments were increased by $15 \%-20 \%$ compared to the control ratio $(0.86 \pm 0.11)$ without significant difference between DON and NIV (Figure 3).

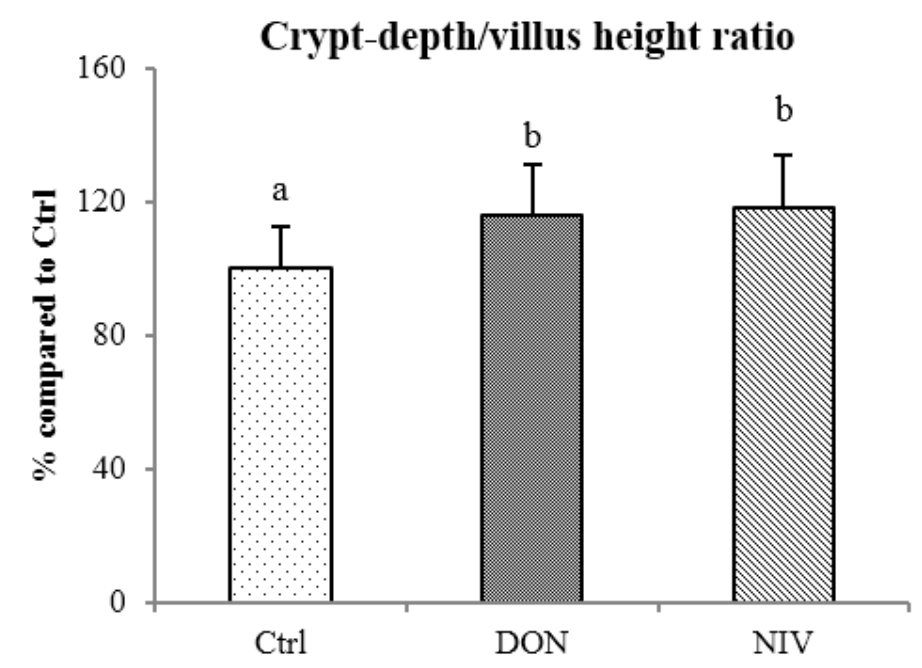

Figure 3. Morphometric analysis of the jejunum loops: crypt-depth to villus-height ratio after DON and NIV exposure at $10 \mu \mathrm{M}$ for $4 \mathrm{~h}$. Mean values \pm SEM expressed as $\%$ of the control group; a, b scripts are different at $p \leq 0.05$; Tukey's test; $n=3$ to 6 loops, 30 well-oriented villi and crypts per loop.

\subsubsection{Effect of DON and NIV Exposure on Proliferation in the Loops}

At the villus tip, a significant decrease was observed in the total cells proliferation compared with control loops. NIV exposed loops showed a significant $30 \%$ decrease in the number of cells proliferating in the mucosa $(p<0.001)$, while DON-exposed loops showed a $13 \%$ decrease compared with the controls (Figure 4A). At the crypt level, proliferative index of crypt enterocytes was increased only after NIV treatment ( $p=0.001$, Figure 4B).

\subsubsection{Effect of DON and NIV Exposure on Apoptosis in the Loops}

At the villus tip, the number of total apoptotic cells was higher in NIV-exposed loops than in the controls. A tendency was detected for the enterocyte apoptotic index $(p=0.057)$ with mean values of 
$2.36 \% \pm 1.12 \%, 2.57 \% \pm 1.52 \%$ and $3.43 \% \pm 2.55 \%$ for the control, DON and NIV, respectively. The total-cell proliferation to total-cell apoptosis ratios at villus tip showed a significant decrease $(p<0.001)$ with values of $6.98 \pm 1.84,5.60 \pm 1.65$ and $3.89 \pm 1.2$ for the controls, DON and NIV, respectively. NIV reduced the total-cell proliferation to total-cell apoptosis ratio at the tip of the villus by $44 \%$ compared to the controls, while DON reduced this ratio by only $20 \%$ (Figure 4D).

In lamina propria, the number of apoptotic cells was significantly increased by NIV $(p<0.001$, Figure 4C).
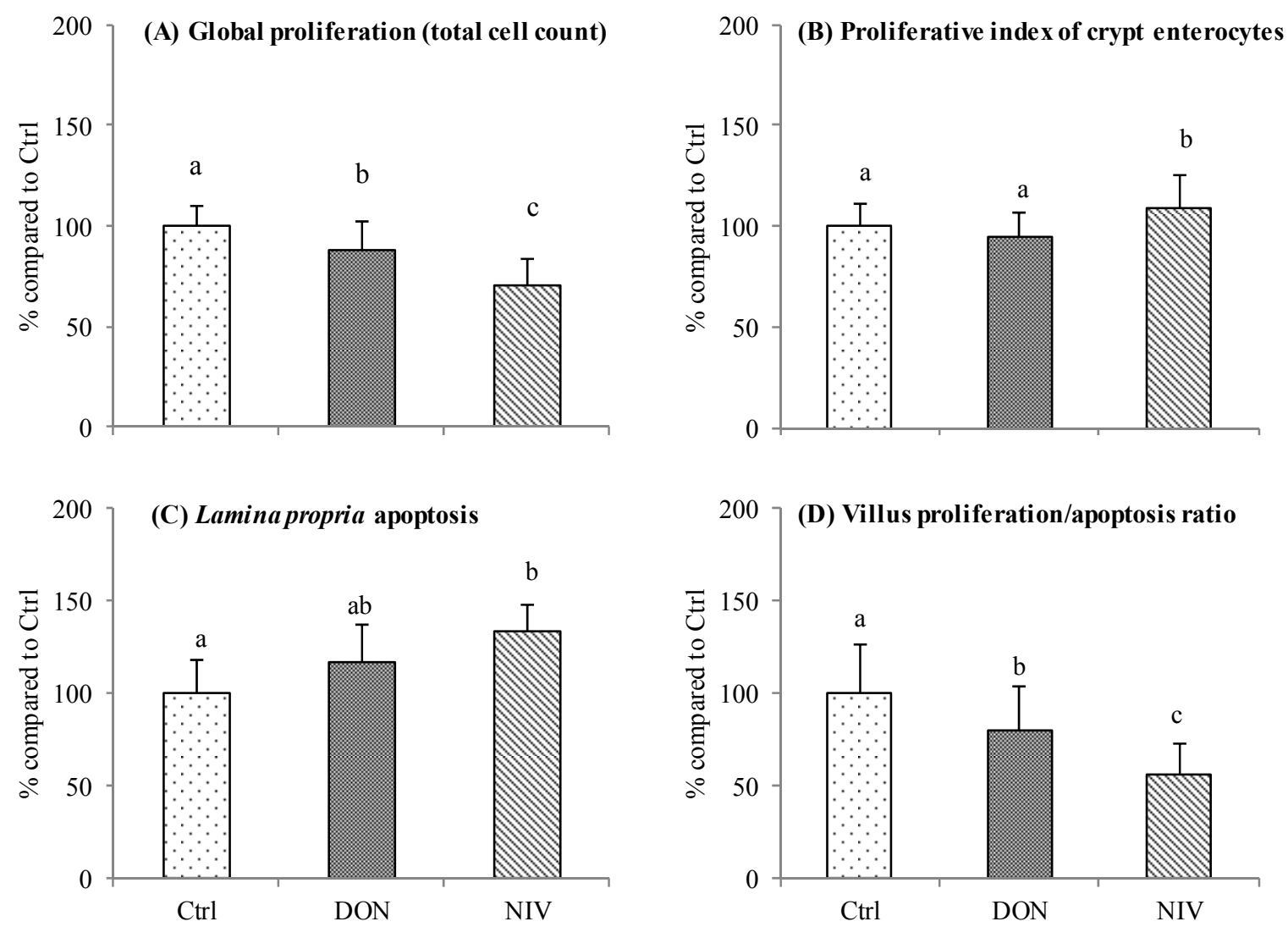

Figure 4. Proliferation and apoptosis in the jejunum loops after DON and NIV exposure at $10 \mu \mathrm{M}$ for $4 \mathrm{~h}$. Mean values \pm SEM expressed as \% of the control group (Ctrl) (A) total cell proliferation at villus tip (upper one-third), $p<0.001$; (B) proliferative index of crypt enterocytes, $p=0.001$; (C) lamina propria apoptosis at villus tip (upper one-third), $p<0.001$; and (D) total proliferating cells to total apoptotic cell ratio, at villus tip $p<0.001$. a, b, c scripts are different at $p \leq 0.05$; Tukey's test; $n=3$ to 6 loops, 20 villi/loop.

\section{Discussion}

Two alternative models were used in this study to analyze intestinal mucosal toxicity, a major target for xenobiotics. An explant model, previously shown to be sensitive [23,24], was first used to demonstrate dose-related toxicity following in vitro exposure to DON and NIV, and a higher toxicity of NIV. This result was then confirmed in vivo, using the intestinal loops model. 


\subsection{The Jejunum Explants and Loops Alternative Models Reduce the Number of Animals}

These two alternative models enabled to reduce the number of animals in experiments, according to the 3Rs recommendations, as the explants or loops are the experimental unit and not the whole animal. Pig intestinal explant culture represent a relevant model for investigating the effects of feed and food contaminants, due to the relevance of the pig model-species in relation to humans, and its high sensitivity to mycotoxins. In the current study, before analyzing the effects of the mycotoxins DON and NIV on the scores, the histological scoring was refined and demonstrated the absence of impact of DMSO up to $0.1 \%$ as solvent. This study illustrates for the first time, to the best of our knowledge, the use of intestinal loops in toxicology. However, the scoring system developed for the explants was not suitable to use in the loops model, because of the inter-loops variations brought about by the surgery-induced vascular changes (edema in the lamina propria). Proliferation and apoptosis were used to assess the in situ mucosal changes, being quantifiable biomarkers specifically affected in vitro and in vivo by the trichothecenes [14,25-28].

\subsection{Acute Exposure to NIV More Toxic in Vitro on Jejunum Mucosa than DON}

Our study revealed higher intestinal mucosa changes after acute exposure to NIV than to DON exposure, both in vitro and in vivo. Following in vitro 4-h single exposure, both trichothecenes induced a dose-related decrease of the explants scores, NIV showing a higher toxicity than DON. Significant changes were observed in explants exposed to 3 and $10 \mu \mathrm{M}$ DON. The main histological changes were focal enterocyte desquamation, moderate atrophy and fusion of villi, in accordance with previous studies $[21,23,27]$. The $30 \%$ reduction of the histological score following $10 \mu \mathrm{M}$ DON was similar to the results obtained by Basso et al. [21] who reported a 37\% decrease of the histological score. In our experiment, all doses of NIV significantly affected the histological scores of the explants. NIV toxicity on intestinal cells in vitro has already been reported. For example, NIV decreased dose-dependently the viability of Caco-2 and IPEC-J2 cells [29,30]. In a previous study, the reduction of IEC-6 viability due to treatment with NIV was related to apoptosis induction [26]. The less severe toxic effect of DON, as compared to NIV, on intestinal explants is also in accordance with previous studies, which demonstrated that NIV exerted a stronger effect than DON on both intestinal and non-intestinal cell lines [26,28,29,31,32].

\subsection{Acute Exposure to NIV More Toxic in Vivo on Jejunum Mucosa than DON}

In the loops model, as in the explants study, the intestinal toxicity of NIV was higher than that of DON. At $10 \mu \mathrm{M}$, both DON and NIV increased the crypt-depth to villus-height ratios, reflecting intestinal damage in vivo, as described in conventional animal experiments [33]. At $10 \mu \mathrm{M}, \mathrm{DON}$ and NIV induced in vivo lamina propria apoptosis and decreased total cells proliferation at the villus tip in the loops model, while only NIV increased the enterocytes proliferation index at the crypt level. So, our study shows that the lamina propria cell populations are the most sensitive target of the jejunum mucosa, after DON and NIV exposure. The major cell populations of lamina propria, besides connective tissue cells, are immune cells, with high proliferative rate, recognized as the most sensitive cells to DON toxicity. These targets have been previously described to explain the modulation of the intestinal immune 
response induced by DON and other trichothecenes [34]. Few studies have analyzed the action of NIV on intestinal morphology. Chronic ingestion of NIV induced gastrointestinal erosions in young pigs ( 2.5 or $5 \mathrm{mg} / \mathrm{kg}$ ) [15], whereas C57BL/6 mice exposed to NIV subchronically or chronically by feeding did not show any alterations in the histological architecture of small intestine [35,36]. These differences could be related to the highest sensitivity of the pig, reported to be the most sensitive species to mycotoxins [6,37]. In the present study, the proliferation mucosal response at crypt level was significant for NIV. These results are in accordance with previous comparative studies of the two toxins, in vitro or in vivo, with other endpoints than the intestinal target. For example, NIV showed higher anorectic potency in mice [38].

\subsection{DON and NIV Induced Apoptosis in Vivo on Loops}

The intestinal effects observed after 4-h exposure to DON and NIV can be mediated by oxidative stress, inducing intestinal cell membrane alteration and apoptosis. DON-induced oxydative stress has been shown in splenic tissue in a rodent model [39], as well as lipid peroxidation in vitro in HepG2 cells exposed to levels similar to the present study [40]. The alterations caused by DON in jejunal explants have been correlated to MAPKs signaling pathway activation [22], and to up-regulation of pro-inflammatory cytokines [41].

\subsection{Relevance of the Results for Risk Characterization}

The effects of mycotoxins were assessed at realistic concentrations in the present study, considering the concentrations of mycotoxins to which the consumer can be exposed via food. The results are therefore of high relevance for risk characterization of DON and NIV exposure. DON concentrations of $0.16-2 \mu \mathrm{g} / \mathrm{mL}(0.5-7 \mu \mathrm{M})$ in the human gut can be considered as realistic [42]. The lower concentration corresponds to the mean estimated daily intake of French adult consumers on a chronic basis [43]. The higher concentration is the simulated levels that can be attained after the consumption of heavily contaminated food, and is occasionally encountered. The amount of NIV in cereal products varies considerably between different countries across the world (from 20-60 $\mu \mathrm{g} / \mathrm{kg}$ in France, to $584-1780 \mu \mathrm{g} / \mathrm{kg}$ in China) [44]. Significant architectural and lesional alterations were observed from doses of $1 \mu \mathrm{M}$ NIV in this study, which is consistent with the levels plausibly encountered in the gastrointestinal tract after the consumption of heavily contaminated food.

\section{Materials and Methods}

\subsection{Animals}

For explants sampling, six 4-5 week-old crossbred piglets were used, housed in the animal facility of the INRA ToxAlim Laboratory (Toulouse, France). For the loops experiment, three two-month-old Large White female pigs were used and housed in the animal facility at INRA Nouzilly. All animals were fasted for $6 \mathrm{~h}$ before explants sampling or loops surgery. The experimental procedures were conducted in accordance with European Guidelines for the Care and Use of Animals for Research Purposes and were approved by the INRA local ethical committees for animal experimentation 
(C2EA-86 for explants, and "Comité d'Ethique en Expérimentation Animale Val de Loire", C2EA-06, for the loops experiments).

\subsection{Toxins}

DON was acquired from Sigma (St Quentin Fallavier, France) and NIV from Waco Pure Chemical Industries LTD (Osaka, Japan). Stock solutions of these mycotoxins were dissolved in dimethyl sulfoxide (DMSO Sigma, Saint-Quentin Fallavier, France) at the following concentrations: $15 \mathrm{mM}$ DON and $10 \mathrm{mM} \mathrm{NIV} \mathrm{for} \mathrm{explants,} \mathrm{and} \mathrm{at} 30 \mathrm{mM}$ DON and NIV for the loops experiments. These stock solutions were stored at $-20^{\circ} \mathrm{C}$. Working dilutions were prepared in William's medium E (WME-Sigma, Saint-Quentin Fallavier, France) for the explants, and in physiological saline solution for the loops. The concentrations range for the dose-response explants study was $0-10 \mu \mathrm{M}$, selected after preliminary explants cultures with 0.1 to $30 \mu \mathrm{M}$ of each toxin.

\subsection{Jejunum Explants Experiment (in Vitro)}

\subsubsection{Jejunal Explants}

The procedure for the culture of explants was as previously described [23,24]. Explants were incubated for $4 \mathrm{~h}$ with WME at $37{ }^{\circ} \mathrm{C}$ under a $\mathrm{CO}_{2}$-controlled atmosphere with orbital shaking. Uncultured control tissue was placed in fixative immediately after dissection, as time 0 controls (T0, $n=12$, two explants/pig). In view of the possible effects of DMSO on intestinal morphology, the final concentration of $0.1 \%$ DMSO corresponding to the highest DMSO concentration in the working dilutions was tested in 42 explants (with and without DMSO: 84 explants). Twelve explants were exposed to purified DON and NIV at each of the concentration 1, 3 and $10 \mu \mathrm{M}$, for $4 \mathrm{~h}$, respectively (two explants/pig for each condition).

\subsubsection{Histological Scoring}

For histological analysis, the explants fixed in 10\% formalin (VWR, Strasbourg, France) were embedded in paraffin (VWR) and sectioned at 3-5 $\mu \mathrm{m}$ thickness parallel to the villus axis and stained with hematoxylin (VWR) and eosin (CML, Nemours, France) (HE) using standard procedures. The resulting slides were analyzed independently by two observers, at $100 \times$ magnification.

The histological changes were evaluated using a tissue scoring system [23] with minor modifications. The scoring system included both architectural and lesional criteria, as shown in Table 1. The maximum score was attributed to the T0 tissue, before incubation, for each criterion. The architectural score included the number of villi per explant and the fusion of villi. This latter was expressed as the 97.5 th percentile of the percentage of fused villi (number of fused villi/non fused villi $100 \times$ ). The score of 3 for villus fusion corresponded to a maximum of $11 \%$ fused villi. At least 25 villi needed to be counted per explant to obtain the score of 3 .

The lesional score included morphology of enterocytes (score 3 for columnar epithelium), the degrees of edema and apoptosis in the lamina propria (score 2 for slight flattening of villi), and the extent of discontinued epithelium qualified as apical denudation of villi. This endpoint was quantified by the 97.5th percentile of the percentage of the villi showing apical denudation (score 3 for T0 explants). 
For explants lesions, score 3 corresponded to a maximum of $10 \%$ apical denudation and scores of 2, 1 , and 0 , to $11 \%-40 \%, 41 \%-70 \%$, and $71 \%-100 \%$, respectively. For lesion of the lamina propria, localized edema was scored as 1 , whereas multifocal edema and apoptosis were scored as 0 . The total score was calculated by taking into account the degree of severity for the lesions (severity factor). For each lesion, the score (according to intensity or observed frequency) was multiplied by the severity factor of 2 . The total score for each explant was then obtained from the sum of each criterion. Each score value was the result of 2 explants/pig/condition. The maximum score (22 points) indicated overall integrity of the intestine. The histological scoring system was applied to compare the microscopic changes observed after 4-h exposure of the explants to DON and NIV.

Table 1. Explants histological scoring: endpoints used and severity factor.

\begin{tabular}{|c|c|c|c|}
\hline Score component & Criteria (severity factor) & End-point & Score \\
\hline \multirow{11}{*}{ Lesional part of the Score } & \multirow{4}{*}{ Enterocytes morphology (2) } & Columnar epithelium & 3 \\
\hline & & $<50 \%$ cuboid epithelium & 2 \\
\hline & & $>50 \%$ cuboid epithelium & 1 \\
\hline & & Flattened epithelium & 0 \\
\hline & \multirow{4}{*}{ Apical denudation of villi (2) } & $0 \%-10 \%$ & 3 \\
\hline & & $11 \%-40 \%$ & 2 \\
\hline & & $41 \%-70 \%$ & 1 \\
\hline & & $71 \%-100 \%$ & 0 \\
\hline & \multirow{3}{*}{ Lesions of lamina propria (2) } & No lesions, slight flattening of villi & 2 \\
\hline & & Localized edema and apoptosis & 1 \\
\hline & & Multifocal edema and apoptosis & 0 \\
\hline \multirow{8}{*}{ Architectural part of the Score } & \multirow{4}{*}{ Villi fusion (1) } & $0 \%-11 \%$ & 3 \\
\hline & & $12 \%-40 \%$ & 2 \\
\hline & & $41 \%-70 \%$ & 1 \\
\hline & & $71 \%-100 \%$ & 0 \\
\hline & \multirow{4}{*}{ Number of villi (1) } & $\geq 25$ & 3 \\
\hline & & $16-24$ & 2 \\
\hline & & $5-15$ & 1 \\
\hline & & $\leq 4$ & 0 \\
\hline
\end{tabular}

\subsection{Jejunum Loops Experiment (in Vivo)}

\subsubsection{Jejunal Loops Injection and Sampling}

A 1-m long segment of intestine was surgically prepared in the jejunum, to constitute the loops as previously described $[19,45]$. This segment was then subdivided into consecutive segments, designated as "loops" (10 cm long, 6 loops), separated by "inter-loops". Three treatments, control (Ctrl), DON and NIV at $10 \mu \mathrm{M}$ concentration were used for each of the 3 pigs ( 1 to 2 loops/pig for each condition, $n=6$ loops for the controls) by injecting $3 \mathrm{~mL}$ of each test condition into each loop. Four hours after surgery, the pigs were euthanized by barbiturate overdose (pentobarbital, Vetoquinol, Lure, France) and the created jejunum-loop segments were collected. These loops were washed twice with physiological serum prior to fixation. In addition, a non-loop segment was sampled and processed in parallel. 


\subsubsection{Histological Processing}

A routine histological processing sequence (from $10 \%$ buffered formalin to paraffin block) was used. Paraffin sections 4- $\mu \mathrm{m}$ thick were stained with $\mathrm{HE}$ to assess architectural changes and immunohistochemically labeled (IHC) to assess proliferation and apoptosis.

\subsubsection{Immunohistochemistry}

Two commercial antibodies were used as previously described [46,47]. Briefly, four-micrometer paraffin-embedded transverse sections from formalin-fixed jejunum specimens were dewaxed in toluene and rehydrated by an acetone bath then deionized water. Antigen retrieval was performed in $10 \mathrm{mM}$ citrate buffer $\mathrm{pH} 6.0$ for $30 \mathrm{~min}$ in a water bath at $95^{\circ} \mathrm{C}$. Cooled sections were then incubated in Dako peroxidase blocking solution (Dako S2023) to quench endogenous peroxidase activity. Non-specific binding was blocked by incubation in normal goat serum (dilution 1:10, Dako X0902) for 20 min at room temperature. The primary antibodies were anti-Ki-67antigen (Dako M7240, dilution 1:50) and anti-active caspase-3 (R\&D system, AF835, dilution 1:300). Sections were incubated with primary antibodies for $50 \mathrm{~min}$ at room temperature (RT). Bound primary antibodies were detected with EnVision $^{\mathrm{TM}}+$ Horse Radish Peroxydase (HRP) Systems (Dako, K4061) $30 \mathrm{~min}$ at RT. Peroxidase activity was revealed by 3,3'-diaminobenzidine tetrahydrochloride substrate (Dako K3468). Finally, sections were counterstained with Harris hematoxylin, dehydrated and coverslipped.

\subsubsection{Architectural Changes}

Eclipse E400 Nikon microscope, with DS-FI camera driven by NIS-D element software (Nikon) was used to capture images (100× magnification) and take the measurements for architectural evaluation of the digestive mucosa. A total of about 30 well-oriented villi and crypts per loop were selected on each section. A villus was measured from the tip to the shoulder (crypt-villus junction) and a crypt was measured from the shoulder to its base (Figure 1c). The crypt-depth to villus-height ratio was calculated to assess the intestinal architectural changes.

\subsubsection{Proliferative and Apoptosis Indexes}

Proliferative and apoptotic cells were counted after immunohistochemistry in several sites on the mucosa. A minimum of 20 well-oriented villi and crypt units were assessed on scanned marked slides (Panoramic 250 Flash II-3D Histech), and analyzed with Pannoramic Viewer software (v. 1.15.2, 3DHISTECH Ltd, Budapest, Hungary,). Proliferative cells were counted in the upper one-third of the villi, i.e. villus tip (positive cells/total cells: lamina propria plus epithelial cells), and in the bottom two-thirds of the crypts from the basis (proliferative index of crypt enterocytes) (Figure 1c). For apoptosis, the total cells counts, lamina propria counts and villus enterocytes counts were measured in villus tip (upper one-third). The enterocyte apoptotic index was calculated by dividing the positive enterocyte number by the total number of enterocytes $(\times 100)$ in the villus tips while the proliferative index of crypt enterocytes was calculated by dividing the number of positive enterocytes by the total number of enterocytes $(\times 100)$ in the crypt bases (Table 2$)$. 
Table 2. Summary of the cell counts and indexes used for assessing proliferation and apoptosis in loops.

\begin{tabular}{|c|c|c|c|}
\hline Endpoint & $\begin{array}{l}\text { Counted } \\
\text { area } \\
\text { (Figure 2) } \\
\end{array}$ & Cells counts & Indexes \\
\hline \multicolumn{4}{|c|}{ Proliferation } \\
\hline & Villus tip & $\begin{array}{l}\text { Total cells: lamina } \\
\text { propria cells }+ \\
\text { enterocytes }\end{array}$ & \\
\hline & Crypt bases & Crypt enterocytes & $\begin{array}{c}\text { Proliferative index of crypt enterocytes: } \\
\text { number of positive enterocytes/total number of } \\
\text { enterocytes }(\times 100)\end{array}$ \\
\hline \multicolumn{4}{|l|}{ Apoptosis } \\
\hline & Villus tip & $\begin{array}{c}\text { Enterocytes } \\
\text { Lamina propria cells } \\
\text { (mainly immune cells) } \\
\text { Total cells: lamina } \\
\text { propria }+ \text { enterocytes }\end{array}$ & $\begin{array}{l}\text { Enterocyte apoptotic index: number of positive } \\
\text { enterocytes/total number of enterocytes }(\times 100)\end{array}$ \\
\hline \multicolumn{4}{|c|}{$\begin{array}{c}\text { Ratio } \\
\text { Proliferation/Apoptosis }\end{array}$} \\
\hline & Villus tip & $\begin{array}{l}\text { Total cells: lamina } \\
\text { propria cells }+ \\
\quad \text { enterocytes }\end{array}$ & $\begin{array}{l}\text { Total-cell proliferation } \\
\text { to total cell apoptosis ratio }\end{array}$ \\
\hline
\end{tabular}

\subsection{Statistical Analysis}

The two experiments were designed as randomized blocks. The explants and loops data are presented as means \pm SEM, expressed as percentages of the control values. Plots of fits versus residuals followed by Bartlett's test, and normal plots of the residuals by Anderson-Darling's test were carried out to confirm the assumptions of homogeneity of variances and the normal distribution of residuals, respectively. If these assumptions did not hold, the data were normalized and homogenized by $\log 10$ or square root transformation prior to being analyzed. All tests were performed using the MINITAB package software (V.13.0, Minitab Inc., State College, PA, USA). The data were analyzed by applying the GLM option of ANOVA analysis, followed by pairwise comparisons, Tukey's or Bonferroni's tests. The datasets for the control loops and non-loops were analyzed with the Wilcoxon matched pairs test and paired t-test for apoptosis and proliferation counts, respectively [48].

\section{Conclusions}

To conclude, the present study shows that pig intestinal explants and loops provide concordant results and permit investigating the digestive effects of DON and NIV with a reduced number of animals (implementation of the 3Rs). Acute NIV exposure induced mucosal changes at a lower concentration than DON in vitro. In vivo, lamina propria cells showed a higher sensitivity than enterocytes to NIV-induced apoptosis. Our results demonstrate that NIV toxicity is not similar to DON on the digestive target, highlighting the need of a specific hazard characterization for NIV health risk assessment. 


\section{Acknowledgments}

This study was supported by the ANR DON \& Co project. S Cheat was supported by doctoral fellowships from TECHNO I Scholar Program, Erasmus Mundus. J. Gerez was supported by Grant No. 593/08 from CAPES/COFECUB.

The authors are grateful to AM Cossalter and the CIRE team for the animals care and handling; to O. Lafaix for helping in the loops experiments; to P. Pinton and S. Desto for helping in explants experiments; to C. Bleuart and I. Pardo for technical assistance for immunohistochemistry; to F. Lyazhri for statistical advice; and to D. Warwick for language editing. The loops surgery was conducted at INRA Centre de recherche Val de Loire (Plate-forme CIRE Chirurgie et Imagerie pour la Recherche et l'Enseignement, UMR Physiologie de la Reproduction et des Comportements (INRA 0085, CNRS 7247, université François-Rabelais de Tours, Institut français du cheval et de l'équitation), 37380 Nouzilly, France).

\section{Author Contributions}

M.K.C., I.P.O., and I.R.L. have contributed to the conception and the design of the study. S.C. and J.C. carried out the loops experiments. J.R.G. and I.A.K. carried out the explants experiments. S.C. and J.R.G. analyzed, interpreted the data, and drafted the manuscript under the direct supervision of M.K.C. M.K.C., I.P.O., I.R.L. and A.P.B. revised critically the article. All authors read and approved the final manuscript.

\section{Conflicts of Interest}

The authors declare no conflict of interest.

\section{References}

1. Smith, L.E.; Stoltzfus, R.J. Prendergast, a. Food Chain Mycotoxin Exposure, Gut Health, and Impaired Growth: A Conceptual Framework. Adv. Nutr. An Int. Rev. J. 2012, 3, 526-531.

2. Pestka, J.J. Deoxynivalenol: Mechanisms of action, human exposure, and toxicological relevance. Arch. Toxicol. 2010, 84, 663-679.

3. Schollenberger, M.; Müller, H.M.; Rüfle, M.; Suchy, S.; Planck, S.; Drochner, W. Survey of Fusarium toxins in foodstuffs of plant origin marketed in Germany. Int. J. Food Microbiol. 2005, 97, 317-326.

4. Tanaka, K.; Kobayashi, H.; Nagata, T.; Manabe, M. Natural occurrence of trichothecenes on lodged and water-damaged domestic rice in Japan. Shokuhin Eiseigaku Zasshi 2004, 45, 63-66.

5. Schothorst, R.C.; van Egmond, H.P. Report from SCOOP task 3.2.10 "collection of occurrence data of Fusarium toxins in food and assessment of dietary intake by the population of EU member states" Subtask: Trichothecenes. Toxicol. Lett. 2004, 153, 133-143.

6. Pestka, J.J.; Smolinski, A.T. Deoxynivalenol: Toxicology and potential effects on humans. J. Toxicol. Environ. Health. B. Crit. Rev. 2005, 8, 39-69.

7. Leblanc, J.-C.; Tard, A.; Volatier, J.-L.; Verger, P. Estimated dietary exposure to principal food mycotoxins from the first French Total Diet Study. Food Addit. Contam. 2005, 22, 652-672. 
8. IARC (International Agency for Research on Cancer). Some Naturally Occurring Substances, Food Items and Constituents, Heterocyclic Aromatic Amines and Mycotoxins. Monograph on the Evaluation of Carcinogenic Risks to Humans; World Health Organization, International Agency for Research on Cancer: Lyon, France, 1993; pp. 397-444.

9. EFSA. Scientific Opinion on risks for animal and public health related to the presence of nivalenol in food and feed. EFSA J. 2013, 11, 1-119, doi:10.2903/j.efsa.2013.3262.

10. Rocha, O.; Ansari, K.; Doohan, F.M. Effects of trichothecene mycotoxins on eukaryotic cells: A review. Food Addit. Contam. 2005, 22, 369-378.

11. Van De Walle, J.; Sergent, T.; Piront, N.; Toussaint, O.; Schneider, Y.-J.; Larondelle, Y. Deoxynivalenol affects in vitro intestinal epithelial cell barrier integrity through inhibition of protein synthesis. Toxicol. Appl. Pharmacol. 2010, 245, 291-298.

12. Maresca, M.; Yahi, N.; Younès-Sakr, L.; Boyron, M.; Caporiccio, B.; Fantini, J. Both direct and indirect effects account for the pro-inflammatory activity of enteropathogenic mycotoxins on the human intestinal epithelium: Stimulation of interleukin-8 secretion, potentiation of interleukin-1 $\beta$ effect and increase in the transepithelial passage of commensal bacteria. Toxicol. Appl. Pharmacol. 2008, 228, 84-92.

13. Grenier, B.; Applegate, T.J. Modulation of intestinal functions following mycotoxin ingestion: Meta-analysis of published experiments in animals. Toxins (Basel) 2013, 5, 396-430.

14. Bracarense, A.-P.F.L.; Lucioli, J.; Grenier, B.; Drociunas Pacheco, G.; Moll, W.-D.; Schatzmayr, G.; Oswald, I.P. Chronic ingestion of deoxynivalenol and fumonisin, alone or in interaction, induces morphological and immunological changes in the intestine of piglets. $\mathrm{Br}$. $J$. Nutr. 2012, 107, 1776-1786.

15. Hedman, R.; Thuvander, A.; Gadhasson, I.; Reverter, M.; Pettersson, H. Influence of dietary nivalenol exposure on gross pathology and selected immunological parameters in young pigs. Nat. Toxins 1997, 5, 238-246.

16. Madej, M.; Lundh, T.; Lindberg, J.E. Effect of exposure to dietary nivalenol on activity of enzymes involved in glutamine catabolism in the epithelium along the gastrointestinal tract of growing pigs. Arch. Tierernahr. 1999, 52, 275-284.

17. Russel, W.M.S.; Burch, R.L. The Principles of Human Experimental Technique; Methuen: London, UK, 1959; pp. 54-66.

18. Girard, F.; Dziva, F.; van Diemen, P.; Phillips, A.D.; Stevens, M.P.; Frankel, G. Adherence of enterohemorrhagic Escherichia coli O157, O26, and O111 strains to bovine intestinal explants ex vivo. Appl. Environ. Microbiol. 2007, 73, 3084-3090.

19. Meurens, F.; Berri, M.; Auray, G.; Melo, S.; Levast, B.; Virlogeux-Payant, I.; Chevaleyre, C.; Gerdts, V.; Salmon, H. Early immune response following Salmonella enterica subspecies enterica serovar Typhimurium infection in porcine jejunal gut loops. Vet. Res. 2009, 40, 41-44.

20. Nietfeld, J.C.; Tyler, D.E.; Harrison, L.R.; Cole, J.R.; Latimer, K.S.; Crowell, W.A. Culture and morphologic features of small intestinal mucosal explants from weaned pigs. Am. J. Vet. Res. 1991, $52,1142-1146$.

21. Basso, K.; Gomes, F.; Bracarense, A.P.L. Deoxynivanelol and fumonisin, alone or in combination, induce changes on intestinal junction complexes and in E-cadherin expression. Toxins (Basel) 2013, $5,2341-2352$. 
22. Lucioli, J.; Pinton, P.; Callu, P.; Laffitte, J.; Grosjean, F.; Kolf-Clauw, M.; Oswald, I.P.; Bracarense, A.P.F.R.L. The food contaminant deoxynivalenol activates the mitogen activated protein kinases in the intestine: Interest of ex vivo models as an alternative to in vivo experiments. Toxicon 2013, 66, $31-36$.

23. Kolf-Clauw, M.; Castellote, J.; Joly, B.; Bourges-Abella, N.; Raymond-Letron, I.; Pinton, P.; Oswald, I.P. Development of a pig jejunal explant culture for studying the gastrointestinal toxicity of the mycotoxin deoxynivalenol: Histopathological analysis. Toxicol. In Vitro 2009, 23, $1580-1584$.

24. Kolf-Clauw, M.; Sassahara, M.; Lucioli, J.; Rubira-Gerez, J.; Alassane-Kpembi, I.; Lyazhri, F.; Borin, C.; Oswald, I.P. The emerging mycotoxin, enniatin B1, down-modulates the gastrointestinal toxicity of T-2 toxin in vitro on intestinal epithelial cells and ex vivo on intestinal explants. Arch. Toxicol. 2013, 87, 2233-2241.

25. Gerez, J.R.; Pinton, P.; Callu, P.; Grosjean, F.; Oswald, I.P.; Bracarense, A.P.F.L. Deoxynivalenol alone or in combination with nivalenol and zearalenone induce systemic histological changes in pigs. Exp. Toxicol. Pathol. 2015, 67, 89-98.

26. Bianco, G.; Fontanella, B.; Severino, L.; Quaroni, A.; Autore, G.; Marzocco, S. Nivalenol and Deoxynivalenol Affect Rat Intestinal Epithelial Cells: A Concentration Related Study. PLoS ONE 2012, 7, doi:10.1371/journal.pone.0052051.

27. Pinton, P.; Tsybulskyy, D.; Lucioli, J.; Laffitte, J.; Callu, P.; Lyazhri, F.; Grosjean, F.; Bracarense, A.P.; Kolf-clauw, M.; Oswald, I.P. Toxicity of deoxynivalenol and its acetylated derivatives on the intestine: Differential effects on morphology, barrier function, tight junction proteins, and mitogen-activated protein kinases. Toxicol. Sci. 2012, 130, 180-190.

28. Marzocco, S.; Russo, R.; Bianco, G.; Autore, G.; Severino, L. Pro-apoptotic effects of nivalenol and deoxynivalenol trichothecenes in J774A.1 murine macrophages. Toxicol. Lett. 2009, 189, 21-26.

29. Alassane-Kpembi, I.; Kolf-Clauw, M.; Gauthier, T.; Abrami, R.; Abiola, F.A.; Oswald, I.P.; Puel, O. New insights into mycotoxin mixtures: The toxicity of low doses of Type B trichothecenes on intestinal epithelial cells is synergistic. Toxicol. Appl. Pharmacol. 2013, 272, 191-198.

30. Wan, L.Y.M.; Turner, P.C.; El-Nezami, H. Individual and combined cytotoxic effects of Fusarium toxins (deoxynivalenol, nivalenol, zearalenone and fumonisins B1) on swine jejunal epithelial cells. Food Chem. Toxicol. 2013, 57, 276-283.

31. Luongo, D.; de Luna, R.; Russo, R.; Severino, L. Effects of four Fusarium toxins (fumonisin B1, alpha-zearalenol, nivalenol and deoxynivalenol) on porcine whole-blood cellular proliferation. Toxicon 2008, 52, 156-162.

32. Minervini, F.; Fornelli, F.; Flynn, K.M. Toxicity and apoptosis induced by the mycotoxins nivalenol, deoxynivalenol and fumonisin B1 in a human erythroleukemia cell line. Toxicol. Vitr. 2004, 18, 21-28.

33. Haschek, W.M.; Rousseaux, C.G.; Wallig, M.A. Fundamentals of Toxicologic Pathology, 2nd ed.; Academic Press-Elsevier: London, UK, 2010; pp. 168-169.

34. Pinton, P.; Oswald, I.P. Effect of deoxynivalenol and other type B trichothecenes on the intestine: A review. Toxins (Basel) 2014, 6, 1615-1643.

35. Yamamura, H.; Kobayashi, T.; Ryu, J.C.; Ueno, Y.; Nakamura, K.; Izumiyama, N.; Ohtsubo, K. Subchronic feeding studies with nivalenol in C57BL/6 mice. Food Chem. Toxicol. 1989, 27, 585-590. 
36. Ryu, J.C.; Ohtsubo, K.; Izumiyama, N.; Nakamura, K.; Tanaka, T.; Yamamura, H.; Ueno, Y. The acute and chronic toxicities of nivalenol in mice. Toxicol. Sci. 1988, 11, 38-47.

37. Kararli, T.T. Comparison of the gastrointestinal anatomy, physiology, and biochemistry of humans and commonly used laboratory animals. Biopharm. Drug Dispos. 1995, 16, 351-380.

38. Wu, W.; Flannery, B.M.; Sugita-Konishi, Y.; Watanabe, M.; Zhang, H.; Pestka, J.J. Comparison of murine anorectic responses to the 8-ketotrichothecenes 3-acetyldeoxynivalenol, 15-acetyldeoxynivalenol, fusarenon $X$ and nivalenol. Food Chem. Toxicol. 2012, 50, 2056-2061.

39. Zhou, H.R.; Islam, Z.; Pestka, J.J. Rapid, sequential activation of mitogen-activated protein kinases and transcription factors precedes proinflammatory cytokine mRNA expression in spleens of mice exposed to the trichothecene vomitoxin. Toxicol. Sci. 2003, 72, 130-142.

40. Zhang, X.; Jiang, L.; Geng, C.; Cao, J.; Zhong, L. The role of oxidative stress in deoxynivalenol-induced DNA damage in HepG2 cells. Toxicon 2009, 54, 513-518.

41. Cano, P.M.; Seeboth, J.; Meurens, F.; Cognie, J.; Abrami, R.; Oswald, I.P.; Guzylack-Piriou, L. Deoxynivalenol as a New Factor in the Persistence of Intestinal Inflammatory Diseases: An Emerging Hypothesis through Possible Modulation of Th17-Mediated Response. PLoS ONE 2013, 8, doi:10.1371/journal.pone.0053647.

42. Sergent, T.; Parys, M.; Garsou, S.; Pussemier, L.; Schneider, Y.J.; Larondelle, Y. Deoxynivalenol transport across human intestinal Caco-2 cells and its effects on cellular metabolism at realistic intestinal concentrations. Toxicol. Lett. 2006, 164, 167-176.

43. Sirot, V.; Fremy, J.M.; Leblanc, J.C. Dietary exposure to mycotoxins and health risk assessment in the second French total diet study. Food Chem. Toxicol. 2013, 52, 1-11.

44. Hsia, C.C.; Wu, Z.Y.; Li, Y.S.; Zhang, F.; Sun, Z.T. Nivalenol, a main Fusarium toxin in dietary foods from high-risk areas of cancer of esophagus and gastric cardia in China, induced benign and malignant tumors in mice. Oncol. Rep. 2004, 12, 449-456.

45. Girard-Misguich, F.; Cognie, J.; Delgado-Ortega, M.; Berthon, P.; Rossignol, C.; Larcher, T.; Melo, S.; Bruel, T.; Guibon, R.; Chérel, Y.; et al. Towards the establishment of a porcine model to study human amebiasis. PLoS ONE 2011, 6, doi:10.1371/journal.pone.0028795.

46. Abot, A.; Fontaine, C.; Raymond-Letron, I.; Flouriot, G.; Adlanmerini, M.; Buscato, M.; Otto, C.; Bergès, H.; Laurell, H.; Gourdy, P.; et al. The AF-1 activation function of estrogen receptor $\alpha$ is necessary and sufficient for uterine epithelial cell proliferation in vivo. Endocrinology 2013, 154, 2222-2233.

47. Laprie, C.; Abadie, J.; Amardeilh, M.F.; Raymond, I.; Delverdier, M. Detection of the Ki-67 proliferation associated nuclear epitope in normal canine tissues using the monoclonal antibody MIB-1. Anat. Histol. Embryol. 1998, 27, 251-256.

48. Festing, M.F.W.; Overend, P.; Borja, M.C.; Berdoy, M. The Design of Animal Experiments: Reducing the Use of Animals in Research through Better Experimental Design; Royal Society of Medicine Press Limited: London, UK, 2002; pp. 38-59.

(C) 2015 by the authors; licensee MDPI, Basel, Switzerland. This article is an open access article distributed under the terms and conditions of the Creative Commons Attribution license (http://creativecommons.org/licenses/by/4.0/). 